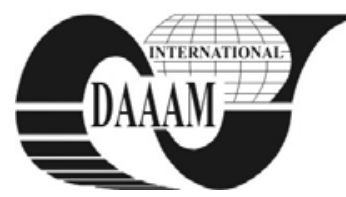

Annals of DAAAM for 2011 \& Proceedings of the 22nd International DAAAM Symposium, Volume 22, No. 1, ISSN 1726-9679 ISBN 978-3-901509-83-4, Editor B. Katalinic, Published by DAAAM International, Vienna, Austria, EU, 2011 Make Harmony between Technology and Nature, and Your Mind will Fly Free as a Bird Annals \& Proceedings of DAAAM International 2011

\title{
BENCHMARK OF COMSOL MULTIPHYSICS VIA IN-DEPTH FLOOR SLAB TEST - STATIONARY CASES
}

\author{
GERLICH, V[ladimir]; PISAN, R[adim] \& ZALESAK, M[artin]
}

\begin{abstract}
The main purpose of this article is an advanced benchmark of COMSOL Multiphysics simulation tool. The program is validated by analytical and comparative verification tests provided by the International Energy Agency in Task 34. Building Energy Simulation Test cases for evaluating building energy simulation software are created and evaluated in COMSOL Multiphysics. Essential goal of this article is evaluating of new simulation environment for building simulations. There are compared numerically calculated thermal flows of stationary and transient heat conduction process from COMSOL Multiphysics with analytical and numerical model outputs presented in Task 34
\end{abstract}

Key words: heat transfer, benchmark, COMSOL Multiphysics, BESTEST, slab-on-grade

\section{INTRODUCTION}

Publication (Schijndel et al., 2008) presents significant tendency in decreasing of energy consumption in building usage in recent years.

Among other aspects, the most important requirements for building simulation software are:

- Stationary and transient simulation of heat and vapor transfer.

- Possibility to compute three-dimensional (or at least twodimensional) models to simulate local effects in constructions e.g. thermal bridges or corners.

- Simulation results should be reproducible and accessible.

There are recommended three types of tests to evaluate accuracy of numerical models (Judkoff \& Neymark, 1995):

- Analytical verifications.

- Comparison with other models (comparative testing).

- Validation with experimental results (experimental validation).

There were created several software benchmarking methods in recent years. One of these benchmarks is Building Energy Simulation Test (BESTEST) provided by the International Energy Agency (IEA) in Task 34 (Neymark \& Judkoff, 2008). There are mutually compared outputs from following software in this benchmark - BASECALC, EnergyPlus, ESP-rBASESIMP, FLUENT, GHT, MATLAB, SUNREL-GC, TRNSYS, VA114-ISO13370. Presented benchmark is based on ground-coupled two-dimensional (2D) thermal conduction, long time constants, and the heat storage of the ground.

COMSOL Multiphysics (COMSOL, 2011) simulation tool is validated by comparative validation via Task 34. Created models were simulated in two program versions (3.5a and 4.1) with minor result differences.

\section{MODELS DESCRIPTION}

There are 17 test cases specified in Task 34, however, there were chosen only stationary cases (6 models) for this paper.

Individual cases are similar to each other with default model parameters which are showed in Table 1.

\begin{tabular}{|c|c|c|}
\hline \multicolumn{2}{|r|}{ Input parameters } & Values \\
\hline \multicolumn{2}{|c|}{ Slab length (L) } & $12 \mathrm{~m}$ \\
\hline \multicolumn{2}{|c|}{ Slab width (B) } & $12 \mathrm{~m}$ \\
\hline \multicolumn{2}{|c|}{ Wall thickness (W) } & $0.24 \mathrm{~m}$ \\
\hline \multicolumn{2}{|c|}{ Inside zone air temperature $(\mathrm{Ti}, \mathrm{a})$} & $30^{\circ} \mathrm{C}$ \\
\hline \multicolumn{2}{|c|}{ Outside air temperature (To,a) } & $10^{\circ} \mathrm{C}$ \\
\hline \multicolumn{2}{|c|}{ Deep ground temperature (Tdg) } & $10^{\circ} \mathrm{C}$ \\
\hline \multicolumn{2}{|c|}{ Deep ground boundary depth (E) } & $15 \mathrm{~m}$ \\
\hline \multicolumn{2}{|c|}{ Far field boundary distance $(\mathrm{F})$} & $15 \mathrm{~m}$ \\
\hline \multicolumn{2}{|c|}{ Int. and ext. heat transfer coefficient } & $100 W \cdot m^{-2} \cdot K^{-1}$ \\
\hline \multirow{3}{*}{$\begin{array}{l}\text { Floor and } \\
\text { slab } \\
\text { parameters }\end{array}$} & Thermal conductivity & $1.9 W \cdot m^{-1} \cdot K^{-1}$ \\
\hline & Density & $1490 \mathrm{~kg} \cdot \mathrm{m}^{-3}$ \\
\hline & Specific heat & $1800 \mathrm{~J} \cdot \mathrm{kg}^{-1} \cdot \mathrm{K}^{-1}$ \\
\hline
\end{tabular}

Tab. 1. Geometry and domains parameters

There are 3 important test case categories from which slabon-grade test presented in Task 34 consists:

- "a" series - allows to demonstrate that the numerical models have been properly applied.

- "b" series - allows to compare more detailed models (minor model differences).

- "c" series - uses boundary conditions compatible with the BASESIMP simulation software.

The "a" cases are in contrast to "b" or "c" cases computed analytically as well as numerically and therefore they serve as primary test of simulation environment ability.

Schematic diagram of modeled geometry is showed in Fig. 1 - elevation zone dimensions are $L x B$ with wall thickness $W$.

There are described specific model differences in contrary to default values in following chapters.

Presented cases drives floor conduction based on the temperature difference between zone air and deep ground boundary condition with high vs. ordinary convective surface coefficients.

\subsection{Case GC10a}

The specific model parameters are described in Table 2.

\subsection{Case GC30a}

The specific model parameters are described in Table 3.

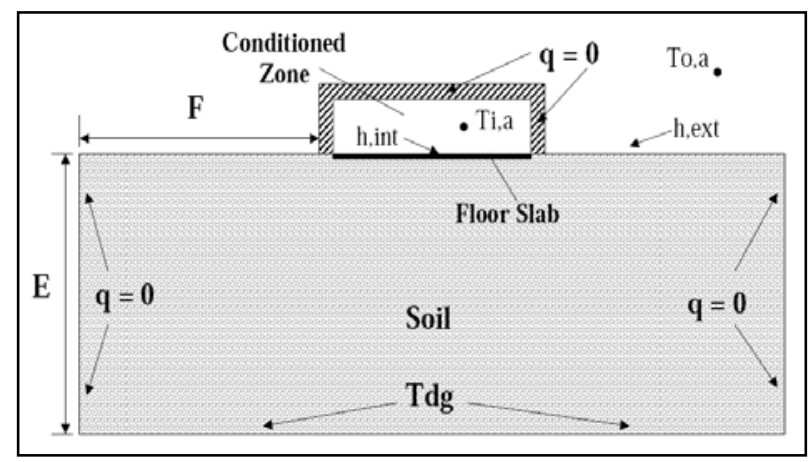

Fig. 1. Schematic model diagram (Neymark \& Judkoff, 2008) 


\begin{tabular}{|c|c|c|c|c|}
\hline 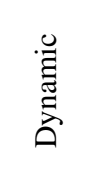 & 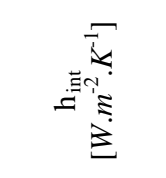 & 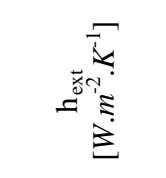 & 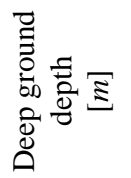 & 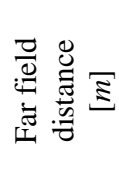 \\
\hline $\begin{array}{c}\text { Steady } \\
\text { state }\end{array}$ & $\begin{array}{c}\text { Direct } \\
\text { temperature }\end{array}$ & $\begin{array}{c}\text { Direct } \\
\text { temperature }\end{array}$ & 40 & 40 \\
\hline
\end{tabular}

Tab. 2. GC10a test case parameters

\begin{tabular}{|c|c|c|c|c|}
\hline Dynamic & $\begin{array}{c}\mathrm{h}_{\text {int }} \\
{\left[W \cdot m^{-2} \cdot K^{-1}\right]}\end{array}$ & $\begin{array}{c}\mathrm{h}_{\text {ext }} \\
{\left[W \cdot m^{-2} \cdot K^{-1}\right]}\end{array}$ & $\begin{array}{c}\text { Deep } \\
\text { ground } \\
\text { depth } \\
{[m]}\end{array}$ & $\begin{array}{c}\text { Far field } \\
\text { distance } \\
{[m]}\end{array}$ \\
\hline $\begin{array}{c}\text { Steady } \\
\text { state }\end{array}$ & Direct T & Direct T & 30 & 20 \\
\hline
\end{tabular}

Tab. 3. GC30a test case parameters

\subsection{Case GC30b}

This case uses default model parameters.

\subsection{Case GC30c}

The model specific parameters are described in Table 4.

\subsection{Case GC60b}

The specific model parameters are described in Table 5.

\subsection{Case GC65b}

The specific model parameters are described in Table 6.

\section{COMSOL MULTIPHYSICS VALIDATION}

The differences between simulation programs do not mean that one of them is better or worse. The only possible conclusion is that similar results imply high probability of correct program outputs.

The comparison between 2 versions of validated program is not showed, because the differences between specific program versions are insignificant (maximally $0.6 \%$ ).

There is showed the comparison of COMSOL Multiphysics and 8 programs presented in Task 34 in Fig. 2. The plot shows the heat flow through room slab. Generally, the conclusion is that that COMSOL Multiphysics results are about $12 \%$ higher in comparison to mean results values of software presented in Task 34.

Results of conductive heat flow through floor differ from $8.3 \%$ to $24.1 \%$ depending on the test case in comparison to mean value of other numerical models. Some of these differences may be explained by the necessity of mechanical heating system modeling via fixed temperature on internal room surface due to impossibility to model fixed domain temperature or time-variant heat source in steady state.

\begin{tabular}{|c|c|c|c|}
\hline Dynamic & $\begin{array}{c}\mathrm{h}_{\text {int }} \\
{\left[W \cdot m^{-2} \cdot K^{-1}\right]}\end{array}$ & $\begin{array}{c}\mathrm{h}_{\text {ext }} \\
{\left[W \cdot m^{-2} \cdot K^{-1}\right]}\end{array}$ & $\begin{array}{c}\text { Far field } \\
\text { distance } \\
{[m]}\end{array}$ \\
\hline Steady state & 7.95 & Direct $\mathrm{T}$ & 8 \\
\hline
\end{tabular}

Tab. 4. GC30c test case parameters

\begin{tabular}{|c|c|}
\hline Dynamic & $\begin{array}{c}\mathrm{h}_{\text {int }} \\
{\left[W \cdot m^{-2} \cdot K^{-1}\right]}\end{array}$ \\
\hline Steady state & 7.95 \\
\hline
\end{tabular}

Tab. 5. GC60b test case parameters

\begin{tabular}{|c|c|c|}
\hline Dynamic & $\begin{array}{c}\mathrm{h}_{\text {int }} \\
{\left[W \cdot m^{-2} \cdot K^{-1}\right]}\end{array}$ & $\begin{array}{c}\mathrm{h}_{\text {ext }} \\
{\left[W \cdot m^{-2} \cdot K^{-1}\right]}\end{array}$ \\
\hline Steady state & 7.95 & 11.95 \\
\hline
\end{tabular}

Tab. 6. GC65b test case parameters

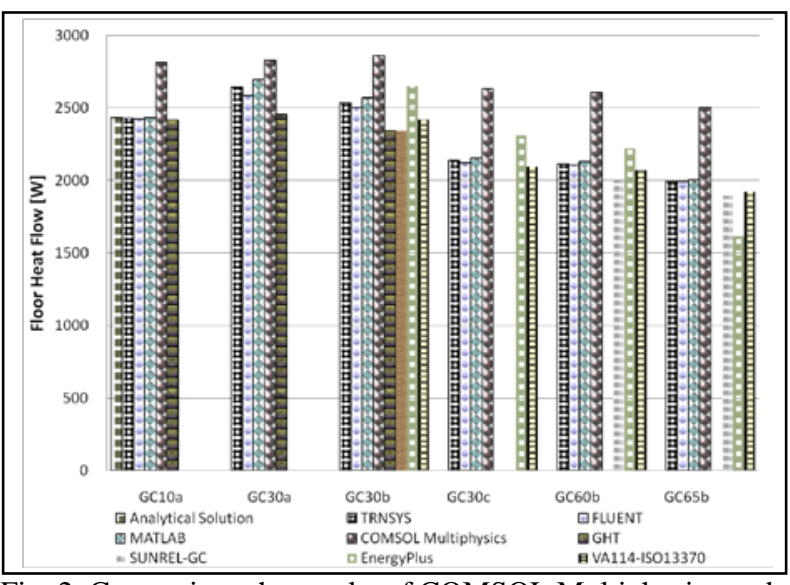

Fig. 2. Comparison the results of COMSOL Multiphysics and tools for building simulation

\section{CONCLUSION}

Versions 3.5a and 4.1 of COMSOL Multiphysics were used to model the ground-coupling models for a slab-on-grade which were specified in IEA BESTEST "In-Depth Diagnostic Cases for Ground Coupled Heart Transfer Related to Slab-on-Grade Construction”.

The paper is limited to 6 results from different stationary cases. The simulation of the transient cases is the future work plan. Differences of tested program in contrast to already validated software are close to results from EnergyPlus validation (Henninger \& Witte, 2010).

\section{ACKNOWLEDGEMENTS}

The work behind the article was supported by the Ministry of Education of the Czech Republic under grant No. MSM 7088352102 and by the European Regional Development Fund under the Project CEBIA-Tech No. CZ.1.05/2.1.00/03.0089 and by the internal grant agency of Tomas Bata University in Zlin with NO. IGA/44/FAI/10/D and IGA/55/FAI/10/D.

\section{REFERENCES}

COMSOL - Multiphysics Modeling and Simulation Software. (2011). Multiphysics Modeling and Simulation Software. Online http://www.comsol.com

Henninger,R. H. \& Witte, M. J. (2010), EnergyPlus Testing with IEA BESTEST In-Depth Ground Coupled Heat Transfer Tests Related to Slab-on-Grade Construction, NREL/TP-550-43388, Arlington Heights, Illinois, US: GARD Analytics. http://apps1.eere.energy.gov/buildings /energyplus/pdfs/energyplus_slab-on-grade_tests.pdf

Judkoff, R. \& Neymark, J. (1995). International Energy Agency Building Energy Simulation Test (BESTEST) and Diagnostic Method. NREL/TP-472-6231, Golden, Colorado, US: National Renewable Energy Laboratory. www.nrel.gov/docs/legosti/old/6231.pdf

Neymark, J. \& Judkoff, R. (2008), International Energy Agency Building Energy Simulation Test and Diagnostic Method (IEA BESTEST) - In-Depth Diagnostic Cases for Ground Coupled Heat Transfer Related to Slab-On-Grade Construction, NREL/TP-550-43388, Golden, Colorado, US: National Renewable Energy Laboratory. http://www.iea-shc.org/publications/downloads/task34Building_Energy_Simulation_Test.pdf

Schijndel, A. W. M van; Schellen, H. L.; Wijffelaars, J. L. \& Zundert, K. van. (2008). Application of an integrated indoor climate, HVAC and showcase. Energy and Buildings.No. 40, 647-653. ISSN 0378-7788 